\title{
Cost Benefit Analysis of UNESCO World Heritage Site Designation in Nova Scotia
}

\author{
BURC KAYAHAN ${ }^{*}$ \\ Department of Economics, Acadia University \\ BRIAN VANBLARCOM ${ }^{\ddagger}$ \\ Department of Economics, Acadia University
}

\begin{abstract}
The objective of this research is to compare the economic benefits (defined as visitor spending) and costs of a UNESCO World Heritage (WH) designation. The study focuses on two sites in Nova Scotia; Old Town Lunenburg (designated as a WH site in 1995) and Grand Pré National Historic Site (which has applied for a WH status). Pre/post designation visitation data from Lunenburg was used to quantify the impact $(6.2 \%)$ in the Nova Scotia context. A proportional (to visitation) impact was projected for Grand Pré. The analysis indicates that the level of visitation is important in determining economic viability and that the rising costs of a WH designation further challenge smaller scale attractions.
\end{abstract}

Keywords: World Heritage designation; UNESCO; Tourism

JEL Classifications: L83

\section{Introduction}

The United Nations Educational, Scientific and Cultural Organization (UNESCO) declares there are significant economic benefits to obtaining a World Heritage (WH) designation. Through an increase in tourism and global awareness, local economies surrounding cultural and natural sites should benefit from having a designation (UNESCO, 2010b). Conventional wisdom is that as a WH designated site, there will be an increase in the level of public awareness which would in turn spark an increase in visitation to the area.

\footnotetext{
* This research was financially supported by an internal grant from the Acadia University. We would like to thank the referee and the editor for their insightful comments, as well as participants at the Mount Allison University, the 2010 Atlantic Canadian Economics Association meetings, and the 2010 Canadian Economic Association meetings, for very helpful discussions.

${ }^{\dagger}$ Email: burc.kayahan@acadiau.ca

‡ Email: brian.vanblarcom@acadiau.ca

(C) 2013 Burc Kayahan and Brian VanBlarcom. Licenced under the Creative Commons AttributionNoncommercial 3.0 Licence (http://creativecommons.org/licenses/by-nc/3.0/). Available at http://rofea.org.
} 
In the hopes of strengthening their position and attractiveness as a cultural destination, The National Historic Site of Grand Pré, located in the Annapolis Valley of Nova Scotia, Canada has applied for a UNESCO WH Site designation. The nomination process began in 2008, has taken three years, cost $\$ 1.3$ million in cash and in kind contributions (Tourism Strategy Interpretation Framework, 2010) and culminated in the official proposal submission in February 2011.

Tourism data from Old Town Lunenburg (established in $1995^{1}$ ) is used to quantify the impact of a heritage designation in the Nova Scotia context. It was assumed that a $\mathrm{WH}$ designation for Grand Pré would have a proportionate impact on tourist visitation ${ }^{2}$. This assumption is based on the cultural similarities of the sites, the geographical proximity to each other and to Halifax (the largest and most visited city in Nova Scotia), and the economic motivation for seeking a WH designation.

This paper will estimate the economic benefits (visitor spending) associated with a World Heritage designation for Lunenburg and compare it with costs of securing and maintaining the designation. Making use of the Lunenburg analysis, the projected economic benefits for Grand Pré National Historic Site will be estimated and compared to the costs associated with the application.

The following section reviews overall tourism trends in Nova Scotia. Section 3 is a review of the literature. This is followed by a comparison the economic benefits and costs associated with a World Heritage Designation, first for Lunenburg (Section 4) and then for Grand Pré (Section 5). The final section discusses the implications of the cost-benefit analysis.

\section{Tourism Trends in Nova Scotia}

Tourism in Nova Scotia has shown moderate growth over the last dozen years, with total visitation being $1.4 \%$ greater in 2008 than it was in $1996 .{ }^{3}$ Visitation has shown considerable variation through time, growing by over $5 \%$ between 1996 and 2000 but falling by $0.6 \%$ between 2001 and 2008. Table 1 shows visitation to Nova Scotia and a its major cultural \& historical attractions (sites were chosen based on those with the greatest attendance, allowing for geographical dispersion across Nova Scotia). In the context of overall visitation trends to the province, the ability of Nova Scotia to attract visitors has been declining with exception of Lunenburg. Over the period from 1996 to 2008, visitation to Luneburg's Fishery Museum $(+3.23 \%)$ exceeded the Nova Scotia growth rate $(+1.35 \%)$, when visitation to all other selected sites in Table 1 fell (by an average of $-4.8 \%$ ). Furthermore, visitation to Lunenburg

\footnotetext{
${ }^{1}$ Joggins Fossil Cliffs, designated as a UNESCO World Heritage Site in late 2008, is not part of the analysis conducted in this paper.

${ }^{2}$ For a detailed discussion of these sites see Appendix A.

${ }^{3}$ Data availability necessitates analysis for the time period of 1999 to 2008.
} 


\section{KAYAHAN, VANBLARCOM Analysis of UNESCO World Heritage Site Designation}

declined at a slower rate than the other sites when overall visitation to Nova Scotia was falling (2001- 2008). The Annapolis Valley of Nova Scotia is one such example of the recent downward trend in tourism. Room nights sold in the region have seen a decline of $16 \%$ from 311,000 in 2000 to 264,000 in 2008. Tourism revenues have decreased $15 \%$ during the same time period (Department of Tourism, Culture and Heritage, 2008). The National Historic Site of Grand Pré (located in the Hamlet of Grand Pré in Nova Scotia's Annapolis Valley) has seen a similar downward trend in visitation. In 1998, 65,115 visited the Site but by 2008, visitation had fallen to 28,516 . This represents a $56 \%$ decrease over a ten year period.

Table 1: Average Percent Change in Visitation to Various Sites in Nova Scotia

\begin{tabular}{|c|c|c|c|}
\hline & $1996-2000$ & $2001-2008$ & $1996-2008$ \\
\hline Visitation to Nova Scotia & $5.15 \%$ & $-0.55 \%$ & $1.35 \%$ \\
\hline Lunenburg - Fishery Museum & $4.18 \%$ & $-1.98 \%$ & $3.23 \%$ \\
Others (Average for sites below) & $-0.85 \%$ & $-6.69 \%$ & $-4.74 \%$ \\
\hline Halifax Citadel & $1.58 \%$ & $-2.33 \%$ & $-0.38 \%$ \\
Fortress of Louisburg & $-3.36 \%$ & $-3.94 \%$ & $-3.75 \%$ \\
Port Royal Fort & $-0.68 \%$ & $-14.28 \%$ & $-7.48 \%$ \\
Grand Pré & $-0.95 \%$ & $-9.23 \%$ & $-6.47 \%$ \\
\hline
\end{tabular}

Figure 1 depicts the downward trend in the number of visitors to Grand Pré. With the exception of 2004, the year of Congrés Mondial Acadien (a world Acadian celebration that resulted in a large increase in the number of visitors to the Site), there has been a consistent decline in the number of visitors from 1998 through to 2008.

Figure 1: Number of Visitors to Grand Pre National Historic Site

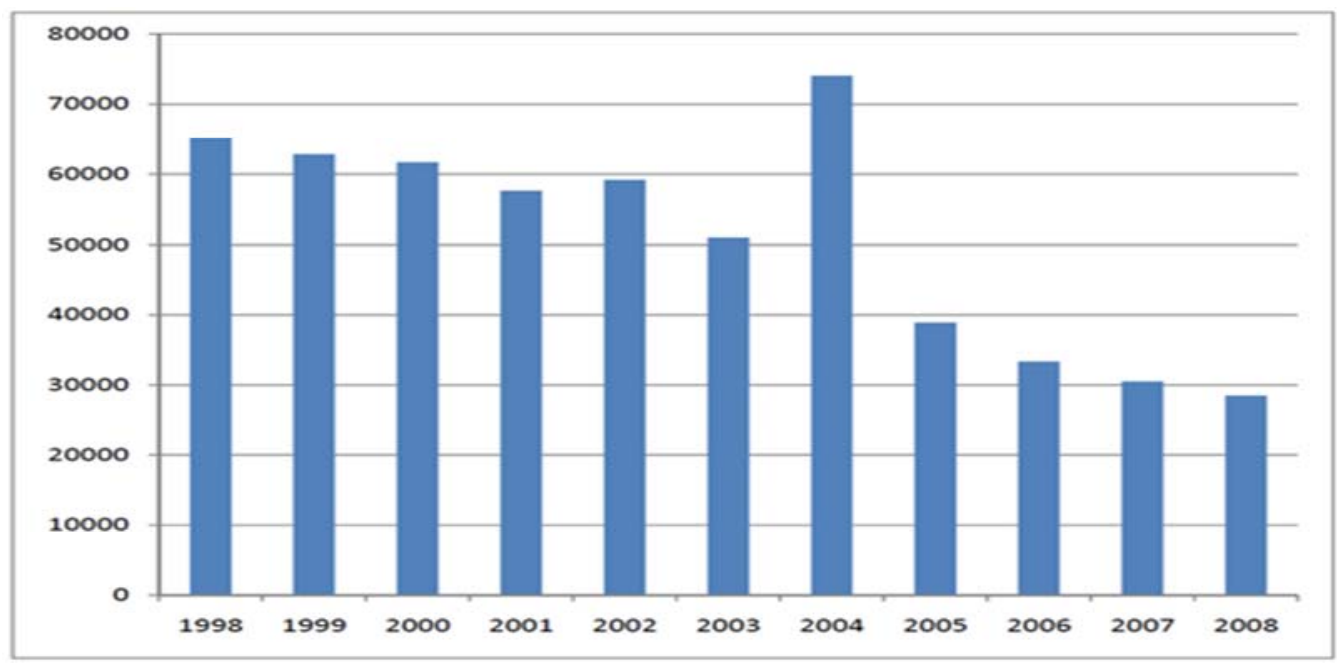


Tourism officials in the Annapolis Valley and Grand Pré are acutely aware of this downward trend and are aiming to reverse it. In hopes of strengthening their position and attractiveness as a cultural destination, The National Historic Site of Grand Pré has applied for a United Nations Educational, Scientific and Cultural Organization (UNESCO) World Heritage Site (WH) designation. Three levels of government will contribute a total of $\$ 1.3$ million to a project that would see the area receive recognition as a worldwide historic and cultural treasure (Chronicle Herald, 2009). It is believed that the status of the designation and related publicity would result in an increase in the number of tourists visiting the site and generate positive economic impacts on the local economy.

\section{LiteratureReview}

The WH convention, established in 1972 by United Nations Educational, Scientific and Cultural Organization (UNESCO), embraces the idea that the international community has a responsibility to cooperate in identification, protection and active conversation of cultural and natural heritage considered to be of outstanding universal value to the whole of humanity (UNESCO, 2010a). As of July 2009, there are 890 properties on the WH list, of which 689 are cultural properties. The WH list includes unique and diverse Sites such as Machu Picchu, the Pyramids of Egypt, Taj Mahal, etc.

Traditionally, cost benefit analyses aimed at assessing the economic value of public goods have attempted to integrate both "use and non-use values" via contingent valuation method (CVM). There has been several studies ${ }^{4}$ that applied the CVM approach to cultural heritage resources. However, as noted by Kim et al. (2007), most of the studies employing CVM for cultural heritage sites have focused on residents' willingness to pay via taxes or donations. These authors also conclude that since cultural assets are a key tourism resource, there is a need to identify "use value" from the perspective of the tourists.

The research to be conducted here examines the economic benefits from tourists visiting two historical sites. Specifically, it measures benefits as local area spending by (non-local) visitors who come to the study areas for the expressed purpose of visiting the sites under consideration. The resulting economic benefits are therefore narrow (by definition) and most relevant from a cost benefit/return on investment perspective.

The early literature on the impact of WH designation focuses mainly on the benefits of designation. Although the benefits from receiving the designation occur in several

4 Beltran and Rojas (1996) - archeological sites in Mexico, Chambers et al. (1998) - cultural resource in Missouri, Pollicino and Madison (2001) - Lincoln Cathedral in England; and Salazar and Marques (2005)- Pirates Tower in Spain. 


\section{KAYAHAN, VANBLARCOM Analysis of UNESCO World Heritage Site Designation}

dimensions ${ }^{5}$ such as conservation, civic pride, learning \& education, etc; there is a large body of literature that investigates the impact of WH designation on tourism. This is primarily due to the change in the motivation of bidding sites for making WH designation applications.

The primary motivation for applying to obtain WH designation was the protection and preservation of the bidding site until the late 1980's. However, since the mid1990s, socioeconomic benefits associated with the designation started to play a large role in motivating the sites to apply for WH designation (Research Consulting Ltd. \& Trends Business Research Ltd., 2009). In particular, sites expect the WH designation to increase visitation and tourism revenues.

Earlier work in the literature supports these expectations. It is often suggested that WH designation increases the popularity of a location or designation with visitors (Ashworth and Turnbridge, 1990; Drost, 1996; Pocock, 1997; Shackley, 1998). A survey of 118 natural WH Sites by Thorsell and Sigaty (2001) reported a total annual visitation of nearly 63 million people. Approximately $13 \%$ of the sites surveyed recorded over 1 million visitors a year with the Great Smoky Mountain in USA leading the group with 9.2 million visitors.

However, empirical studies conducted in the last decade produce mixed results. On the one hand, several studies found positive but relatively small impact of WH designation on visitation $^{6}$. Galvin (1997) reports that visitation to WH parks in U.S. were $5.2 \%$ greater than the visitation in the rest of the national parks without the WH title during the 1990-95 period. Studies that survey a sample of $\mathrm{WH}$ sites $^{7}$ found that at least $40 \%$ of the sites surveyed reported an increase in visitor numbers since gaining WH Site inscription. Most of the sites reported an average increase of $1-5 \%$ per annum since designation. However, a causal link between WH listing and increased visitation over and above existing tourism trends was regarded as somewhat tenuous, particularly for the sites that were major attractions prior to heritage listing. Sites that are well known globally such as Pyramids of Egypt, Taj Mahal, etc., appear to benefit less from world heritage brand marketing relative to the sites with a lower global profile. Finally, WH status leads to an increase in the number of international visitors, who tend to stay longer and to spend more than domestic visitors (Van der Aa, 2010).

5 See reports produced by PricewaterhouseCoopers Ltd. (2007) and Research Consulting Ltd. \& Trends Business Research Ltd. (2009) for a detailed description.

${ }^{6}$ There are several other studies that find a positive association between the WH designation and visitation numbers (Buckley, 2004; Soares et al., 2007; Blacik, 2007; Bojic', 2007), however, the evidence presented in these studies is not conclusive since they suffer from problems such as missing/incomplete data on visitation numbers, using changes in visitation perceived by officials rather than the actual changes and failure to isolate the impact of $\mathrm{WH}$ site inscription from other factors that would have affected the visitation.

${ }^{7}$ Hall and Piggin (2001) conducted a survey of 44 WH managers in OECD countries. Van der Aa (2010) analyzed the change in visitation following inscription using a sample of 86 world heritage sites. 
On the other hand, recent studies highlight the limited role of the WH designation and emphasize the importance of an environment in which the benefits from designation can be maximized. Prud'homme $(2008)^{8}$ evaluates the impact of designation on the economic development of a site and concludes that the impact of WH designation on local development is largely exaggerated. In particular, he identifies the motivation for becoming a WH site and the actions of the site following the designation as determinants of the socio-economic impact of the designation.

Results from the Research Consulting Ltd. \& Trends Business Research Ltd. (2009) study, which aims to identify the best practices from existing WH sites that successfully converted the socio-economic potential of designation into an actual advantage, support Prud'homme's results. They report that approximately $70-80 \%$ of $\mathrm{WH}$ sites appear to be doing little or nothing with the designation directly to bring about significant socio-economic impacts: “...they are not failing to deliver economic gain, they are not even trying." (p. 22). Furthermore, they separate the WH sites into four categories based on the motivation for application.

1. A celebration Designation: Treat WH as a celebration or reward designation for heritage already preserved; don't use WH to achieve socio-economic impacts since they see the achievement itself as the reward.

2. A heritage SOS designation: Treat WH as an emergency attention designation for unique heritage at risk; mainly focus on preserving the heritage.

3. A Marketing/Qualify Logo/Brand: Treat WH designation as a marketing tool and quality brand to promote the development of tourism.

4. A Place Making Catalyst: Treats WH designation as a powerful catalyst for economic development using heritage to develop powerful identities for places and to make fundamental changes to places; use designation to generate wider socio-economic impacts.

The authors concluded that management organization and stakeholders' perception of WH status matters. They argue that small to non-existent economic impacts of WH designation found in the early literature are not surprising since most of the sites that were analyzed have celebration or heritage SOS designation motives, hence they lack the motivation to promote the WH designation to its fullest extent for generating economic gains.

The literature on the costs of obtaining a WH status is relatively scarce compared with that related to the benefits. However, there is a growing interest on the costs of $\mathrm{WH}$ designation recently due to the significant increase in the costs of WH application. PricewaterhouseCoopers Ltd. (2007) executive study, commissioned by the Department for

8 In a report produced for the World Heritage Centre of UNESCO, Prud'homme provides a detailed review of the studies conducted by Gravari-Barbas and Jacquot (2008), Nicot and Ozdirlik (2008) and Talandier (2008). 


\section{KAYAHAN, VANBLARCOM Analysis of UNESCO World Heritage Site Designation}

Culture Media and Sport and Historic Scotland, investigates the benefits and costs of World Heritage Site status in the UK by conducting a survey of 17 of the 24 UK domestic WH sites. This study reports the impact of WH status on visitation estimate as $0-3 \%$.

The site-specific costs associated with WH designation ${ }^{9}$ can be grouped under three main categories. In order to apply, sites go through a bidding process where they submit a nomination form demonstrating that they meet the WH site criteria set by UNESCO World Heritage Centre. On average it takes 5 years for a site in UK to be added to the tentative list and to get approval. Moreover, the bidding process entails costs associated with preparation of the management plan, conducting supportive studies and consultation provided by third parties. PricewaterhouseCoopers Ltd. (2007) estimates ${ }^{10}$ the overall cost of making a bid for a site in UK between $£ 420 \mathrm{k}-570 \mathrm{k}$, which is equivalent to $\$ 670 \mathrm{k}-908 \mathrm{k}$ CAD as of September 2010. It should be noted that the costs associated with the bidding process would be larger for the sites with a relatively more complex ownership.

Secondly, sites that successfully receive the WH site inscription would incur costs in order to meet UNESCO requirements such as monitoring, periodic reporting and maintenance of the sites. The management costs would depend on the size and complexity of the site. PricewaterhouseCoopers Ltd. (2007) estimates the management costs to be somewhere between $£ 190 \mathrm{k}-615 \mathrm{k}$, which is equivalent to $\$ 310 \mathrm{k}-\$ 980 \mathrm{kCAD}$. The study also points out to the fact that the extent of the management costs borne by the local authorities depends on the site's ability to leverage funding from other sources. Moreover, local communities may face indirect costs that would take the form of congestion and constraints on development (i.e. housing, employment, environmental risks, etc.). These indirect costs can be seen as the opportunity costs of gaining the WH status, hence they are site specific and difficult to quantify empirically.

Finally, there are costs associated with the WH status related activities arising from improvement of existing sites such as infrastructure (accessibility and tourism), visitor experience and marketing that are also difficult to quantify since they would mainly depend on the type and degree of improvements, which are likely to be site specific.

It should be noted that the bidding costs also depend on the degree of competition among sites and they are likely to increase with the increasing level of competition, which might deter potential sites from applying in the future and cause the sites that are already on the list to reevaluate the feasibility of WH status. In fact, findings from a recent survey conducted in

\footnotetext{
${ }^{9}$ There is also a literature (Frey and Steiner, 2010; Gamboni, 2001; Meskell, 2002; Mossetto, 1994) on the overall negative aspects of the WH designation.

${ }^{10}$ The study makes certain assumptions regarding the structure of the management and attributes of the site, hence the actual site specific costs of making a bid are likely to vary depending on the attributes of the site such as the ownership structure, global profile of the site, location, motivation for application, marketing activity and nature of the site.
} 
China, (which occupies the third place in the world with 40 sites in WH list and has 35 projects that have formally made a bid for designation) shows that $74 \%$ of the people think it is better to spend more money on the actual protection of the places of interest and $68 \%$ of the people think that it is unnecessary to apply for world heritage declaration to protect the places of interest (People's Daily Online, 2010). Xinning County located in Hunan Province is estimated to have spent more than 1 billion yuan (approximately $\$ 152$ million CAD) on the application of the recently designated site of Danxia landform and sites involved with the application.

\section{Economic Benefits and Costs of a WH Designation: Lunenburg}

\subsection{The Regression Model}

Regression analysis is a statistical tool used to determine the relationship between a dependent variable and independent variables. Regression analysis has been conducted to isolate the impact that a WH designation has on tourism visitation to Lunenburg. The resulting impact on visitation is then combined with the results of a visitor expenditure survey in to order estimate the impact of a World Heritage designation on total visitor expenditures. The following regression specification is adopted to estimate the impact of $\mathrm{WH}$ designation on visitation to Lunenburg:

$$
\text { PVNSL }_{t}=\beta 0+\beta 1 \text { UNESCO }_{t}+\beta 2 \text { USCANFX }_{t}+\beta 3 \text { INFLATION }_{t}+\beta 4 \text { EVENT }_{t}+u t
$$

The dependent variable, PVNSL, represents the percentage of visitors coming to Nova Scotia that visit Lunenburg. Unfortunately there exists no direct data on tourism visitation to Lunenburg before or after the WH designation. Therefore, visitation to Lunenburg is estimated using various data collected from the Nova Scotia Department of Tourism. ${ }^{11}$

UNESCO is an indicator variable that takes the value of zero before the World Heritage designation and the value of one after the designation. The goal of the regression is to isolate the $\beta 1$ coefficient in order to quantify the impact of the WH designation on visitation to Lunenburg. The USCANFX variable represents the US-Canada exchange rate, which denotes the value of one Canadian dollar in terms of American dollars. The INFLATION variable measures the annual percentage change in the price of gasoline in Nova Scotia. Finally, the EVENT variable is introduced in order to account for temporary increases in tourism due to particular events in the area of interest. This variable takes the value ' 1 ' if in that particular year there was a high profile tourism event that occurred in the region and the value ' 0 ' otherwise.

\footnotetext{
${ }^{11}$ The details of the procedure for constructing the dependent variable is explained in the Appendix B.
} 
KAYAHAN, VANBLARCOM Analysis of UNESCO World Heritage Site Designation

\subsection{Data}

The independent variables of UNESCO, USCANFX, INFLATION, and EVENTS, as well as the dependent variable (the percentage change in visitors who come to Nova Scotia that visit Lunenburg) were each assessed between the years of 1990 to 2008. The data for the exchange rate and inflation rate ${ }^{12}$ were retrieved from Statistics Canada (CANSIM). The EVENTS and UNESCO variables were dummy variables taking the value of " 0 " in the years where the variable did not apply, and "1" when the variable was applicable.

\subsection{Regression Results}

This section presents the results from the regression analysis of the data and the direct economic impact estimates of WH designation to Lunenburg. Regression results are presented in Table $2 .^{13}$

Table 2: Regression Results for Lunenburg 1990-2008 period

\begin{tabular}{|l|r|c|c|r|}
\hline Variable & Coeff. & Std. Error & t-statistic & p-value \\
\hline Intercept & 4.412 & 1.450 & 3.042 & 0.009 \\
UNESCO & 1.240 & 0.326 & 3.807 & 0.002 \\
USCANFX & 0.032 & 1.857 & 0.017 & 0.986 \\
INFLATION & -0.020 & 0.108 & -0.186 & 0.855 \\
EVENT & 0.613 & 0.353 & 1.735 & 0.107 \\
\hline R-squared & 0.621 & F-statistic & 5.32 \\
Adjusted R-squared & 0.504 & Prob (F-stat) & 0.009 \\
Observations & 18 & Root MSE & 0.609
\end{tabular}

The UNESCO coefficient is estimated to be $1.24^{14}$ implying that the designation at Old Town Lunenburg has led to a $1.24 \%$ increase in the share of visitors to Nova Scotia people that went to Lunenburg. Estimated coefficient is statistically significant at the $5 \%$ level. ${ }^{15} \mathrm{We}$ can

${ }^{12}$ Inflation rate is calculated as a percentage change in the annual CPI (2005 basket with 2002 as the base year) series and the exchange rate is calculated by taking the averages of the monthly CAN-USD series (noon spot rate) in a calendar year.

${ }^{13} \mathrm{We}$ focus on the interpretation of the UNESCO coefficient in the main text since it is the primary coefficient of interest. However, a brief interpretation of the remaining coefficient estimates is presented in Appendix B.

${ }^{14}$ In order to test the robustness of our results, we estimated a reduced specification of the model by excluding the insignificant variables (USCANFX and INFLATION). The UNESCO coefficient, in this reduced specification, is estimated to be 1.301 and is statistically significant at the $1 \%$ level.

${ }^{15}$ Given the time-series nature of our data, our specification might suffer from serial correlation which would result in biased (downward) estimates of the standard errors of coefficients if present. 
compute the resulting percentage change in tourism visitation to Lunenburg using this positive and significant value of visitation attributable to the WH designation.

\subsection{WH Designation Effect on Visitation to Lunenburg}

The average annual number of visitors to Nova Scotia from 1999 to 2008 is estimated to be 2.14 million people (Nova Scotia Department of Tourism). The percentage of non-resident visitors to Nova Scotia who visit Lunenburg is estimated to be $20 \%$ by the Nova Scotia Exit Survey conducted in 2004. The annual number of visitors to Lunenburg can be calculated using this information as follows:

Average number of visitors to Lunenburg 1999-2008 $=2.14$ million $* 20 \%=428000$

Therefore, it is estimated that the average number of visitors to Lunenburg was 428,000 during the 1999-2008 period. Given the fact that the WH designation is estimated to increase the share of visitation to Lunenburg by $1.24 \%$, the annual change in the number of tourists to Lunenburg in the 1999-2008 period due to WH designation can be computed as follows:

Change in visitation to Lunenburg due to $\mathrm{UNESCO}=2.14$ million $* 1.24 \%=26536$

In other words, the WH designation in Lunenburg has resulted in an increase in the annual visitation by 26,536 people during the $1999-2008$ period. Finally, the numbers from equations (2) and (3) can be used to express the impact of a WH designation as a percentage change in the visitation to Lunenburg.

$$
\text { Impact of UNESCO designation as \% of people visiting }=\frac{26536}{428000}=6.2 \%
$$

The estimated impact of the WH designation for Lunenburg is in line with the estimates reported in the literature. Galvin (1997) reported that visitation to WH parks in U.S. were 5.2\% more than the visitation in the rest of the national parks without the WH title during the 199095 period. Most of the managers of WH sites in OECD countries, surveyed by Hall and Piggin (2001), reported an average increase of $1-5 \%$ per annum since designation.

Therefore, we conducted Breusch-Godfrey LM test to check for the presence of serial correlation in our specification. P-values of the test statistic for the first-order and second-order serial correlation are reported to be 0.36 and 0.22 respectively by STATA. Therefore, we do not find any evidence of serial correlation in our specification. 
Pricewaterhouse-Coopers Ltd. (2007) executive study estimated the impact of WH status on visitation to the World Heritage sites in the UK as $0-3 \%$. In fact, it is not surprising for the estimated impact in Lunenburg to be slightly larger than the estimates reported in the literature since the impact of designation is conjectured to be larger for sites that are not wellknown prior to designation (Van der Aa, 2010; PricewaterhouseCoopers Ltd., 2007). Moreover, we can first construct a confidence interval for the UNESCO regression coefficient at the $95 \%$ level of confidence, and then convert the boundaries of this interval to percentage of people visiting Lunenburg. The confidence interval constructed in this manner produced an interval estimate for the WH designation impact as $2.68 \%-9.72 \%$, which contains the estimates reported in the previous literature. Evidence supporting the significance of the WH designation impact in Lunenburg was noted previously (see Table 1 and related discussion).

\subsection{WH Designation Effect on Visitor Expenditures in Lunenburg}

Average expenditures for visitors was estimated via a survey conducted in the summer of 2009 at the Old Town Lunenburg. The survey asked the spending habits of visitors (i.e. accommodation, food, retail, etc.) Average spending per trip per person is estimated to be \$143. The survey excluded the following observations:

1. persons who lived within a 30 minute drive; and

2. persons whose primary purpose of the trip was not visiting the WH site of Old Town Lunenburg.

A total of 311 surveys were collected. Combining the increased visitation figures with average spending per visitor will generate annual expenditures attributable to the WH designation. The direct economic impact economic impact equals $(\$ 143 * 26,536)=\$ 3.71$ million.

\subsection{Costs of a WH Designation for Lunenburg}

The costs of preparing the UNESCO World Heritage bid in the early 1990s and ongoing commitment to uphold the guidelines contained in the designation achieved in 1995 are based on an interview with Larry Haughn the principal individual (along with officials with Parks Canada) in preparing the bid. He is now the Deputy Mayor for the Town of Lunenburg. He estimates the costs as follows.

Lunenburg WH Designation related Costs (current dollars):

1. Direct/indirect costs of preparing the application: $\$ 10,000$ per year, 1993-1995, Town of Lunenburg \& Parks Canada

2. Management report : Produced in 1998 , cost $\$ 90,000$.

3. Time spent on World Heritage related activities (by law, zoning issues, etc.): $\$ 5,000$ per year 
4. Total estimated costs (2009 dollars) 1993-2009 related to UNESCO designation costs of $\$ 231,000$.

\subsection{Comparing Benefits and Costs of a WH Designation for Lunenburg}

Cost benefit analysis compares the ratio of benefits to costs for a given project (benefits/costs). The costs relate to the expenses incurred during the process of obtaining a WH designation and managing a WH site. The economic benefits are defined as tourism related spending by visitors who are drawn to the area as a result of the WH designation. Tourism related projects generate benefits and costs that can occur at different points in time, so adjustments for the opportunity cost of capital are necessary. Typically all/most of the costs occur in the early years, with the benefits occurring in subsequent years. A present value (PV) calculation adjusts for differing times frames for benefits and costs. Cost benefit analysis allows an entity to decide whether or not the benefits of a given initiative outweigh the costs.

Table 3 shows the benefits and costs for the Lunenburg WH designation for the years 1993- 2009.

Table 3: Yearly Benefits \& Costs of a World Heritage Designation for Lunenburg

\begin{tabular}{|l|r|r|r|}
\hline Year & \multicolumn{1}{|c|}{ Benefits } & \multicolumn{1}{c|}{ Costs } & \multicolumn{1}{l|}{ Net Benefits } \\
\hline 1993 & $\$ 0$ & $\$ 13,763$ & $-\$ 13,763$ \\
1994 & $\$ 0$ & $\$ 13,602$ & $-\$ 13,602$ \\
1995 & $\$ 0$ & $\$ 13,430$ & $-\$ 13,430$ \\
1996 & $\$ 3,168,354$ & $\$ 6,593$ & $\$ 3,161,761$ \\
1997 & $\$ 3,382,202$ & $\$ 6,461$ & $\$ 3,375,741$ \\
1998 & $\$ 3,697,477$ & $\$ 121,948$ & $\$ 3,575,529$ \\
1999 & $\$ 3,918,772$ & $\$ 6,314$ & $\$ 3,912,458$ \\
2000 & $\$ 3,862,030$ & $\$ 6,102$ & $\$ 3,855,928$ \\
2001 & $\$ 3,801,209$ & $\$ 5,989$ & $\$ 3,795,220$ \\
2002 & $\$ 3,866,285$ & $\$ 5,815$ & $\$ 3,860,470$ \\
2003 & $\$ 3,800,677$ & $\$ 5,624$ & $\$ 3,795,053$ \\
2004 & $\$ 3,915,226$ & $\$ 5,522$ & $\$ 3,909,703$ \\
2005 & $\$ 3,748,545$ & $\$ 5,374$ & $\$ 3,743,170$ \\
2006 & $\$ 3,750,318$ & $\$ 5,267$ & $\$ 3,745,051$ \\
2007 & $\$ 3,794,648$ & $\$ 5,169$ & $\$ 3,789,479$ \\
2008 & $\$ 3,687,901$ & $\$ 5,079$ & $\$ 3,682,823$ \\
2009 & $\$ 3,710,421$ & $\$ 5,000$ & $\$ 3,705,421$ \\
\hline
\end{tabular}

The third column shows the annual net benefits calculated by subtracting the costs from the benefits. Note that the net benefits are negative from 1993-1995 as costs were incurred in preparing the WH designation but without any corresponding benefits. Since the designation, 


\section{KAYAHAN, VANBLARCOM Analysis of UNESCO World Heritage Site Designation}

the benefits have been positive in each year.

Assuming the base case discount rate of $4 \%{ }^{16}$, the net present value of the WH designation or Lunenburg (the stream of net benefits) is \$36 million (2009 dollars), as calculated below:

$$
N P V=\sum_{t=1}^{n} \frac{B_{t}-C_{t}}{(1+r)^{t}}=\$ 36 \text { million }
$$

where $\left(B_{t}-C_{t}\right)$ denotes the net benefit $t$ years from present, $r$ denotes the discount rate, and $n$ denotes the total number of periods in the time horizon considered. In other words, the present value of the benefits outweigh the present value of the costs by $\$ 36$ million (2009 dollars) over the time period from 1993 to 2009. It can be concluded that the WH designation has clearly had a large positive economic benefit for Lunenburg.

\subsection{Sensitivity of Benefits/Costs of a WH Designation for Lunenburg}

This subsection provides a sensitivity analysis for the present value of the net benefits associated with a WH designation in Lunenburg. In particular, discount rates of 2\%, 4\% (base case) and $6 \%$, along with the estimated WH designation impact on visitation of $2.7 \%, 6.2 \%$ (base case) and 9.7\% (confidence interval estimates for the estimated regression coefficient at the $95 \%$ level of confidence) are presented Table 4 .

Table 4: NPV of a WH Designation for Lunenburg

\begin{tabular}{|l|c|c|c|}
\hline \multirow{2}{*}{ Discount rate } & \multicolumn{3}{|c|}{ Visitation Change } \\
\cline { 2 - 4 } & $2.70 \%$ & $6.20 \%$ & $9.70 \%$ \\
\hline $2 \%$ & $\$ 18,609,780$ & $\$ 43,008,688$ & $\$ 67,407,595$ \\
$4 \%$ & $\$ 15,571,977$ & $\$ 36,005,912$ & $\$ 56,439,846$ \\
$6 \%$ & $\$ 13,148,028$ & $\$ 30,416,805$ & $\$ 47,685,582$ \\
\hline IRR & $368 \%$ & $516 \%$ & $615 \%$ \\
\hline Break Even Year & 4 & 4 & 4 \\
\hline
\end{tabular}

Results indicate a positive net present value under all discount rates and visitation scenarios, ranging from $\$ 13$ million to $\$ 67$ million. Major factors contributing to the large net positive economic impact relates to the relatively low cost of designation along with the significant impact on visitation and associated spending. In all cases, the internal rates of return are in excess of $350 \%$ and the present value of total benefits exceeds total costs in year four (the first year that benefits accrue).

\footnotetext{
${ }^{16}$ See Boardman et al. (2009) for a discussion social discount rates in Canada.
} 


\section{Economic Benefits and Costs of a WH Designation: Grand Pré}

\subsection{Impact of a WH Designation on the Level of Visitation to Grand Pré}

As mentioned in section 4, the $6.2 \%$ increase in the level of visitation to Lunenburg due to the designation will be used to estimate the change in visitation numbers to Grand Pré if it were to receive a designation. ${ }^{17}$ Applying this percentage increase in visitation to Grand Pré will provide an estimate of the expected increase in the number of tourists to the Site. The economic impact of a WH designation for Grand Pré is estimated under two scenarios:

1. Historical Scenario: Under the historical scenario, the expected visitation to Grand Pré Historic site is calculated by taking an average of the visitation numbers for the 19982008 period. The average number of visitors for this time period is 51,000 people.

2. Projected Scenario - 2009 forecast based on the recent visitation trend in Grand Pré Under the projected scenario, the projected number of visitors is calculated using the trend in visitation and adjusting for any events (such as the Congrés Mondial Acadien in 2004) that would have caused an unusual change in visitation. In 2009 no attractions were scheduled and therefore the downward trend in visitation to Grand Pré is expected to persist into the near future. Visitation under this scenario is forecasted to be 24,652 using a linear time trend.

\subsection{Grand Pré Visitor Survey Results}

In the summer of 2008, a survey was conducted of visitors (non-local residents) whose primary purpose of visiting the area was to visit Grand Pré Historic Site. A total of 278 surveys were completed. Average spending per person visiting the site of Grand Pré is estimated to be $\$ 66.70$.

\subsection{WH Designation Effect on Visitor Expenditures in Grand Pré}

Direct economic impacts of the WH designation on the local economy can be computed by combining the increased visitation figures (historical and projected) with the average spending figures. Visitation under the historical scenario is calculated to be 51,000 people. Local attendees ${ }^{18}$ (representing 5\% of the total, based on the 2008 Grand Pré survey) are excluded from the impact analysis given that their expenditures are not incremental to the local economy. Excluding locals, the historic average number of visitors for this period is 48,450. Applying a $6.2 \%$ increase in visitation due to a $\mathrm{WH}$ designation to the average

${ }^{17}$ The justification of this assumption is discussed in Appendix A.

${ }^{18}$ We exclude local attendees to achieve consistency in estimation of economic impacts. Recall that local attendees were excluded from survey; therefore the historical visitation series for Grand Pre', which naturally includes local attendees, need to be corrected to be consistent in computing the economic impacts of designation. 


\section{KAYAHAN, VANBLARCOM Analysis of UNESCO World Heritage Site Designation}

number of visitors to Grand Pré yields an estimated increase of 3,004 visitors. Taking this number of new tourists, multiplying it by our average spending per visitor of $\$ 66.70$, we find the direct spending of new visitors in the local economy to be approximately $\$ 200,360$.

The forecasted visitation to Grand Pré under the projected scenario is 24,652 people. Reducing this figure by $5 \%$ to account for local attendees gives a total of 23,419 visitors projected to visit in 2009 . Using the $6.2 \%$ forecasted increase in visitation due to $\mathrm{WH}$ designation translates into 1,452 more people visiting the Site because of a WH designation. The predicted spending of new visitors is $\$ 96,849$, calculated via multiplying the number of new tourists by the average spending per visitor of $\$ 66.70$. A summary of the historical and projected economic impacts is found in Table 5.

Table 5: Estimated impact of a potential WH designation on visitation to Grand Pré

\begin{tabular}{|l|c|c|}
\hline & Historical(1998-2008) & Projected(2009) \\
\hline Average number of visitors & 48,450 & 23,419 \\
Increase in number of visitors & 3,004 & 1,452 \\
Average spending per visitor & $\$ 66.70$ & $\$ 66.70$ \\
Spending of new visitors & $\$ 200,360$ & $\$ 96,847$ \\
\hline
\end{tabular}

\subsection{Cost of a WH Designation for Grand Pré}

The cost of preparing the Grand Pré UNESCO World Heritage bid is estimated at \$1.3 million over three years, 2008-2010 (Nomination Grand Pré, 2009). These expenditures were spread equally into expenditures of $\$ 441,000$ from 2008 to 2010. Part of the WH bid funding is through grants from Federal, Provincial and Municipal Governments. Additionally, there are significant "in-kind" contributions from Parks Canada, Kings Community Economic Development Agency, Society Promotion Grand Pré, the Municipality of Kings and the Province of Nova Scotia. The dollar values of the "in kind" contributions are part of the bid total cost of $\$ 1.3$ million.

\subsection{Sensitivity of Benefits/Costs of a WH Designation for Grand Pré}

Table 6 shows the net present value (benefits less costs) for the Grand Pré WH designation for a 25 year time horizon (2008-2032) under a variety of scenarios and discount rates. The annual net benefits are calculated by subtracting the costs from the benefits. The 
low/high/base case visitor spending are calculated using the visitation sensitivity analysis. ${ }^{19}$ The net benefits are negative from 2008 to 2010 as bid costs are incurred with no corresponding benefits. The WH designation had a significant but relatively small economic impact on Grand Pré, with base case visitation and mid-range discount rate of:

1. Historical NPV $=\$ 1.35$ million (2009 dollars)

2. Projected NPV $=\$ 20,000$ (2009 dollars).

Table 6: Net Present Value of Benefits of a potential WH designation - Grand Pré

\begin{tabular}{|c|c|c|c|c|c|c|}
\hline & \multicolumn{3}{|c|}{ Historical (1998-2008) } & \multicolumn{3}{|c|}{ Projected(2009) } \\
\hline & Low & Base & High & Low & Base & High \\
\hline$\Delta$ Visits & 1,298 & 3,004 & 4,710 & 627 & 1,452 & 2,277 \\
\hline 2008 & $-\$ 441,290$ & $-\$ 441,290$ & $-\$ 441,290$ & - & - & \\
\hline 2009 & $-\$ 441,290$ & $-\$ 441,290$ & $-\$ 441,290$ & $-\$ 441,290$ & $-\$ 441,290$ & $-\$ 441,290$ \\
\hline 2010 & $-\$ 441,290$ & $-\$ 441,290$ & $-\$ 441,290$ & $-\$ 441,290$ & $-\$ 441,290$ & $-\$ 441,290$ \\
\hline 2011 & $\$ 86,652$ & $\$ 200,360$ & $\$ 314,158$ & $\$ 41,841$ & $\$ 96,847$ & $\$ 151,853$ \\
\hline 2012 & $\$ 86,652$ & $\$ 200,360$ & $\$ 314,158$ & $\$ 41,841$ & $\$ 96,847$ & $\$ 151,853$ \\
\hline$\ldots$ & $\ldots$ & & $\ldots$ & $\ldots$ & $\ldots$ & $\ldots$ \\
\hline 2032 & $\$ 86,652$ & $\$ 200,360$ & $\$ 314,158$ & $\$ 41,841$ & $\$ 96,847$ & $\$ 151,853$ \\
\hline NPV if $r=2 \%$ & $\$ 340,553$ & $\$ 2,061,279$ & $\$ 3,782,005$ & $-\$ 492,874$ & $\$ 338,864$ & $\$ 1,170,60$ \\
\hline NPV if $r=4 \%$ & $\$ 20,877$ & $\$ 1,349,405$ & $\$ 2,677,934$ & $-\$ 622,591$ & $\$ 19,572$ & $\$ 661,736$ \\
\hline NPV if $r=6 \%$ & $-\$ 199,390$ & $\$ 846,137$ & $\$ 1,891,665$ & $-\$ 705,787$ & $-\$ 200,417$ & $\$ 304,954$ \\
\hline $\operatorname{IRR}(\%)$ & 4.16 & 12.38 & 18.70 & -1.92 & 4.15 & 8.51 \\
\hline Break-Even if $r=2 \%$ & $20 \mathrm{yrs}$ & $11 \mathrm{yrs}$ & $8 \mathrm{yrs}$ & $47 \mathrm{yrs}$ & $18 \mathrm{yrs}$ & $14 \mathrm{yrs}$ \\
\hline Break-Even if $r=4 \%$ & $25 \mathrm{yrs}$ & $12 \mathrm{yrs}$ & $9 \mathrm{yrs}$ & $>100 \mathrm{yrs}$ & $25 \mathrm{yrs}$ & $15 \mathrm{yrs}$ \\
\hline Break-Even if $\mathrm{r}=6 \%$ & $38 \mathrm{yrs}$ & $13 \mathrm{yrs}$ & $9 \mathrm{yrs}$ & $>100 \mathrm{yrs}$ & $39 \mathrm{yrs}$ & $18 \mathrm{yrs}$ \\
\hline
\end{tabular}

The economic feasibility (positive NPV) of the designation depends on the visitation figures and the discount rates. The bid is feasible for the historical scenario in all cases but the low visitation/highest discount rate case and is marginal under the low visitation/mid-discount rate case. The bid is not feasible under the projected scenario in all low visitation cases, regardless of the discount rate. The bid remains unfeasible in the (historical) base visitation case with high discount rate and is marginal under the base visitation/mid-range discount rate. Under the "projected" visitation scenario, the bid is feasible under all high visitation cases, becomes marginal under the base case visitation/mid-range discount rate but is not feasible under for

\footnotetext{
19 "Low" and "high" cases are computed by constructing a confidence interval at the $95 \%$ significance level around the estimated UNESCO coefficient that quantifies the impact of designation on visitation. A detailed description is presented in Appendix C.
} 


\section{KAYAHAN, VANBLARCOM Analysis of UNESCO World Heritage Site Designation}

any low visitation cases.

The internal rate of return ranges from $-1.92 \%$ in the most conservative case, to $+18.70 \%$ in the most optimistic case. The internal rate of return is negative in the "projected" scenario/low visitation case", approximates the mid-rage discount rate " $4 \%$ " in the "historical" scenario/low visitation and "projected" scenario/base visitation case and exceeds $4 \%$ in all other cases. The number of years for the economic benefits to exceed its costs range from less than 10 years in the "historical scenario/high visitation" case to more than 100 years in the "projected scenario/low visitation" case. The fundamental reasons for the smaller impact (relative to Lunenburg) are the significantly higher cost of designation (almost six times higher) and the reduced economic benefits due to the lower volume of visitors (about one eighth).

\section{Conclusion}

The objective of this paper to estimate the economic impact associated with a World Heritage Site designation for Grand Pré and Lunenburg Nova Scotia; and compare the economic benefits with the costs of obtaining the WH designation. Tourism data from Lunenburg, established as a UNESCO Site in 1995, was used to quantify the impact. Regression analysis, observing a time period covering both before and after the designation at the Site, taking into account the designation and other potentially influential variables on tourism, generated a percentage change in visitors to Lunenburg due to a WH designation to be a $6.2 \%$. Applying this percentage increase in visitation at Lunenburg to Grand Pré, provided an estimate of the expected increase in the number of tourists. The applicability of the Lunenburg WH impacts to Grand Pré was based on the following facts:

1. They are both cultural $\&$ historic attractions.

2. They are located a one hour car trip from each other and a similar distance from the capital city of Halifax (Nova Scotia's primary tourist destination).

3. Economic benefits from attracting tourists constituting as a prime motivation for designation in both cases.

The WH designation for Lunenburg is estimated to generate significant annual economic benefits of $\$ 3.7$ million (2009\$). Total UNESCO designation related costs (bid preparation costs and related administrative costs) for the period 1993 to 2009 totaled only $\$ 231,000$ (2009 dollars). Consequently Lunenburg has large net (benefits less costs) present value (1993-2009) of \$36 million (2009 dollars).

A Grand Pré WH designation is expected to generate proportional (yet smaller in absolute terms) economic benefits. Annual impacts are estimated at approximately $\$ 200,000$ under the historic visitation scenario (base case) and $\$ 100,000$ under the projected visitation scenario (base case). The cost of preparing the Grand Pré designation bid is $\$ 1.3$ million. The 
net present value over a 25 year time horizon (2008-2032) is relatively small under the historic scenario at $\$ 1.35$ million and marginal under the projected case with $\$ 20,000$. The number of years for WH designations economic benefits to exceed its costs range from less than 10 in the "historical scenario/high visitation" cases to more than 100 in the "projected scenario/low visitation" cases.

The present value of net benefits for Grand Pré is considerably less than Lunenburg due to the much smaller scale of visitation. The importance of the scale of the site (in terms of visitation) is consistent with findings of Research Consulting Ltd. \& Trends Business Research Ltd. (2009), who noted that perhaps only larger sites could justify the cost of inscription and management of a WH site to use it as an effective catalyst for regenerative economic change.

From an economic perspective, the WH for Lunenburg appears to have been very favourable. The economic feasibility of the Grand Pré WH designation is sensitive to the visitation scenarios and is not feasible under some of the more "conservative visitation/discount rate" cases. Recent studies (Prud'homme, 2008; Research Consulting Ltd. \& Trends Business Research Ltd., 2009) indicate that WH status alone is not sufficient to stimulate transformational change and the local authorities must plan to capitalize upon WH status as much as is possible, while investing in the other links in the chain to gain benefit. A WH designation can also act as a basis of advertising for the Site. A UNESCO WH designation is a very recognizable title and can be used to promote visitation to the area on a national and international scale. Such a strategy may be more effective for sites that are not internationally known (Van der Aa, 2010), which would appear applicable to Lunenburg in 1995 and Grand Pré in 2008. An effective advertising campaign featuring the WH designation may allow Grand Pré to return to its historic average for visitors. While the impact of a WH designation is dependent on tourism trends (driven by such things recessions, exchange rates, price and availability of substitutes/complements), the feasibility of the designation for Grand Pré depends on the degree to which the WH designation can reverse the downward trend in visitation.

While the results of this paper are likely specific to the study area, the conclusions could be of interest to many stakeholders including UNESCO and individual countries/regions that have WH sites. Further research is needed that compares the economic benefits and costs of a WH designation. Firstly, within the narrowly defined benefits of increased visitor spending and narrowly defined costs of obtaining/managing such a designation. Secondly, in terms of the broader based social/economic/environmental benefits and costs. 
KAYAHAN, VANBLARCOM Analysis of UNESCO World Heritage Site Designation

\section{References}

Ashworth, G. and Turnbridge, J. (1990), The Tourist Historic City. London: Belhaven.

Beltran, E. and Rojas, M. (1996), Diversified funding methods in Mexican archeology, Annals of Tourism Research, Volume 23 (2), pp. 463-478

Blacik, L. (2007), A Critical Assessment of the Impact of World Heritage Site Designation in Sub-Saharan Africa, Training Workshop. Retrieved from http://digitalcollections. sit.edu/cgi/viewcontent.cgi?article=1155\&context=isp_collection.

Boardman, A. E., Moore, M. A., Vining, A. R. and DeCivita, P. (2009), Social Discount Rates in Proposed Social Discount Rate(s) for Canada Based on Future Growth, Government of Canada: Economic Policy Research Program Working Paper 039.

Bojic', M. (2007), Preserving World Heritage in Southeastern Europe, Training Workshop. Retrieved from http://www.preserveworldheritage.org/en/Training-Workshop/ Plitvice/Docs_Pics/Presentations/Mirna_Bojic.pdf.

Buckley, R. (2004), The Effects of World Heritage Listing on Tourism to Australian National Parks, Journal of Sustainable Tourism 12, 70-84.

Chambers, C. M., Chambers, P. F. and Whitehead, J. (1998), Contingent valuation of a quasipublic good: Validity, reliability, and application to valuing an historic site.

Chronicle Herald (2009), Acadians out to tell "story of Grand Pré to the rest of the world": Governments contribute to UNESCO world heritage site effort. Retrieved from http://thechronicleherald.ca/cedrom_archives/February17th,2009.

Department of Tourism, Culture and Heritage (2008), Tourism Insights. Retrieved from http://www.gov.ns.ca/tch/pubs/insights/AbsPage.aspx?siteid=1\&lang=1\&id=1.

Drost, J. E. (1996), Developing Sustainable Tourism for World Heritage Sites, Annals of Tourism Research 23(2), 479-492.

Frey, B. S. and Steiner, L. (2010), World Heritage List: Does it make sense?, Institute of Empirical Research in Economics, Working Paper No.484.

Galvin, D. (1997), Testimony on H.R. 901, The American Land Sovereignty Protection Act, US 105th Congress House of Representatives Committee on Resources. Washington DC.

Gamboni, D. (2001), World Heritage: shield or target?, Conservation, 16 (2), 5-11

Graham, R. E. (1998), Lunenburg World Heritage Community Strategy report. Retrieved from http://www.nominationgrandpre.ca/Documents/Documents/Lunenburg/Lunenburg\% 20World\%20Heritage\%20Community\%20Strategy.pdf.

Gravari-Barbas, M. and Jacquot, S. (2008), Impacts socio-économiques de l'inscription d'un site sur la liste du patrimoine mondial: Une revue de la littérature, Polygraphié, Rapport pour l'Unesco, Polygraphié, Juillet 2008

Hall, C. M. and Piggin, R. (2001), Tourism and World Heritage in OECD countries, Tourism Recreation Research 26(1), 103-105. 
Hamilton, L., Haedrich, R. L. and Duncan, C. M. (2004), Above and Below the Water: Social/Ecological Transformation in Northwest Newfoundland, Population and Environment 25(3), 195-215.

Johnston, A. and Kerr, W. (2004), Grand Pré: Heart of Acadie, Canada: Nimbus Publishing. Johnston, A. J. (2009), Nomination Grand Pré: Report on the Proposed Outstanding Universal Value. Retrieved from http://www.nominationgrandpre.ca/Documents/ Documents/gp/Report\%20OUV\%20working\%20group\%20January\%202009.pdf.

Kennedy, J. (1997), At the Crossroads: Newfoundland and Labrador Communities in a Changing International Context, The Canadian Review of Sociology and Anthropology 34(3), 297- 318 .

Kim, S., Wong, K. and Cho, M. (2007), Assessing the economic value of a world heritage site and willingness-to-pay determinants: A case of Changdeok Palace, Tourism Management, 28(1), 317-322

Meskell, L. (2002), Negative Heritage and Past Mastering in Archaeology, Anthropological Quarterly, 75(3), 557-574.

Mossetto, G. (1994), The Economic Dilemma of Heritage Preservation, in Alan Peacock and Ilde Rizzo (eds.) Cultural Economics and Cultural Policies, Dordrecht:Kluwer.

Nicot, B. and Ozdirlik, B. (2008), Les impacts socio-économiques de l'inscription sur la liste $\mathrm{du}$ Patrimoine Mondial: Deux comparaisons en Turquie, Rapport pour l'Unesco, Polygraphié, juillet 2008, 111-153

Nomination Grand Pré (2009), Website. Retrieved from http://www.nominationgrandpre. ca/.

People's Daily Online (2010), Survey: Chinese question high cost of world heritage applications. Retrieved from http://english.peopledaily.com.cn/90001/90776/90882/ 7117460.html.

Pocock, D. (1997), Some Reflections on World Heritage, Area 29(3), 260-268.

Pollicino, M. and Madison, D. (2001), Valuing benefits of cleaning the Lincoln cathedral,

Journal of Cultural Economics, 25,131-148

PricewaterhouseCoopers Ltd. (2007), The Costs and Benefits of UK World Heritage

Status: A literature review for the Department for Culture, Media and Sport.

Retrieved from http://www.culture.gov.uk/images/publications/PwC casestudies.pdf.

Prud'homme, R. (2008), The Socio-Economic Impacts of Inclusion of a Site on the

World Heritage List: Three Studies. Retrieved from

http://www.rprudhomme.com/resources/ 2008+Impact+Liste+Patrimoine.pdf.

Research Consulting Ltd. \& Trends Business Research Ltd. (2009), World Heritage

Status:Is There Opportunity for Economic Gain? Retrieved from

http://www.lakesWH.co.uk/ documents/WHTheEconomicGainFinalReport.pdf.

Salazar, S. and Marques, J. (2005), Valuing cultural heritage: The social benefits of restoring and old Arab tower. Journal of Cultural Heritage, 6, 69-77 
KAYAHAN, VANBLARCOM Analysis of UNESCO World Heritage Site Designation

Shackley, M. (1998), Visitor Management: Case Studies from World Heritage Sites, Oxford: Butterworth-Heinemann

Soares, J., Neves, J. and Fernandes, F. (2007), The Impact of World Heritage Classification on The Development of Tourist Destinations: The Sintra Case Study, in Proceedings of the $2^{\text {nd }}$ International Conference of Advances in Tourism Economics, 13 to 14 April 2007 , Vila Nova de Sto André, Portugal

Talandier (M), 2008, L'impact du classement Unesco sur le développement économique local. Une analyse économétrique des facteurs d'attractivité territoriale sur le cas de la France métropolitaine, Rapport pour l'Unesco, Juin 2008, Polygraphié

Thorsell, J. and Sigaty, T. (2001), Visitor human use in World Heritage natural sites: A global inventory, Tourism Recreation Research 26(1), 85-101.

Tourism Strategy Interpretation Framework (2010), Final Report. Retrieved from http://www.nominationgrandpre.ca/Documents/Documents/gp/Final\%20Report\% 20\%20February\%2024\%202010.pdf.

UNESCO (2010a), About World Heritage, Website. http://whc.unesco.org/en/about/.

UNESCO (2010b), Benefits of Ratification, Website. Retrieved from http://whc.unesco. org/en/convention\#Benefits-of-Ratification.

UNESCO (2010c), The List, Website. Retrieved from http://whc.unesco.org/en/list/ 741.

Van der Aa, B. (2010), Preserving the heritage of humanity? Obtaining World Heritage Status and the impacts of listing, PhD Dissertation, University of Groningen. c http://irs.ub. rug.nl/ppn/27585387X.

\section{Appendices}

\section{Appendix A - Background Information on Grand Pré and Lunenburg}

\section{A.1 Background: Grand Pré Historic Site}

Grand-Pré was founded by Acadian in the late 1600s. However Acadian residents were expelled from Grand Pré starting 1755. After the deportation of the Acadians, the lands were resettled by New England Planters in 1760. In the 1920s the Dominion Atlantic Railway developed the Grand Pré memorial park to attract tourists. It made the community a tourism destination as well as a memorial to the Acadian people (Johnston and Kerr, 2004). A WH designation for Grand-Pré is based on its Outstanding Universal Value (OUV). Outstanding Universal Value of a World Heritage Site refers to its cultural and/or natural significance, which is so exceptional that it is of common importance for present and future generations of all humanity. Nomination Grand-Pré proposes outstanding universal value based on: 
(i) It is an exceptional testimony to a cultural tradition,

(ii) It is an outstanding example of a traditional land-use that is representative of human inter- action with a distinctive environment,

(iii) Through its evocative memorials to a people who overcame a tragedy of a forced migration, the Acadian Deportation, Grand Pré is a symbol of hope, perseverance and pride for all humanity (Johnston, 2009).

\section{A.2 Background: Old Town Lunenburg}

The Town of Lunenburg, was formally established in 1753 as the first British Colonial settlement in Nova Scotia outside of Halifax. A vibrant and stable economy was built on farming, fishing, ship building and ocean-based commerce. The WH designation for Lunenburg, granted in December of 1995, relates to its outstanding universal value as follows. Old Town Lunen- burg is the best surviving example of a planned British colonial settlement in North America. Established in 1753, it has retained its original layout and overall appearance. Old Town Lunen- burg is a well preserved example of 18th century British colonial urban community and culture designed for and based on the offshore Atlantic fishery. Of special importance is its diversified and well-preserved vernacular architectural tradition, which spans over 250 years (UNESCO, 2010c).

\section{A.3 Similarities Between Grand Pré Historic Site and Old Town Lunenburg}

As noted in the introduction, a fundamental assumption of the analysis is that Grand Pré Historic site would experience a percentage change in visitation similar to Lunenburg if it was successfully designated as a WH site. This assumption is justified for three reasons. Firstly, both of these sites can be classified as a "cultural" ${ }^{20}$ site in terms of WH categorization, hence they are likely to attract a similar type of visitors. Secondly, both sites are are located in rural counties with comparable populations, approximately a one hour drive $(100 \mathrm{~km})$ from each other and from Nova Scotia's largest city and most visited destination, the city of Halifax. (see Figure 2). Finally, both sites share the same motivation of promoting tourism to maximize the economic benefits of WH designation. Applying the filter proposed by Research Consulting Ltd. \& Trends Business Research Ltd. (2009) to categorize sites based on their motivation for application, Old Town Luneburg can be classified under the "A Place Making Catalyst" category. The collapse of Atlantic Fisheries around 1990's had a negative impact on Lunenburg's economy, which was mainly dependent on traditional industries of

\footnotetext{
20 "Cultural heritage" is defined in Article 1 of the UNESCO convention as monuments, groups of buildings and sites that are of outstanding universal value from the point of view of history, art or science and aesthetic, from the ethnological or anthropological point of view.
} 
fishing and shipbuilding. The decline of the Canadian marine industry forced local economies such as Lunenburg to di- versify its economic activities to achieve a sustainable economy. ${ }^{21}$ Tourism was identified as a key industry prior to designation and was used as a tool for making a fundamental change by incorporating tourism industry to the local economy. This view is clearly outlined at the World Heritage community strategy report (Graham, 1998) ${ }^{22}$ prepared for UNESCO:

In applying for the designation ... the Town Council was aware that World Heritage Listing presents the community with tremendous opportunities for new economic development through international marketing, increased tourism, new cultural industries, and rejuvenation of local business and industry (section 1.01) Most importantly, the community must understand that sustaining tourism requires a long-term business strategy. It is also true that a community like Lunenburg can influence the kind of tourism it receives, by positioning itself as a higher quality, better experience, which will shift the market mix away from lowyield, high volume tourism towards high-yield lower volume tourism. (section 7.2).

Figure 2: Map of Nova Scotia: Grand Pré and Lunenburg

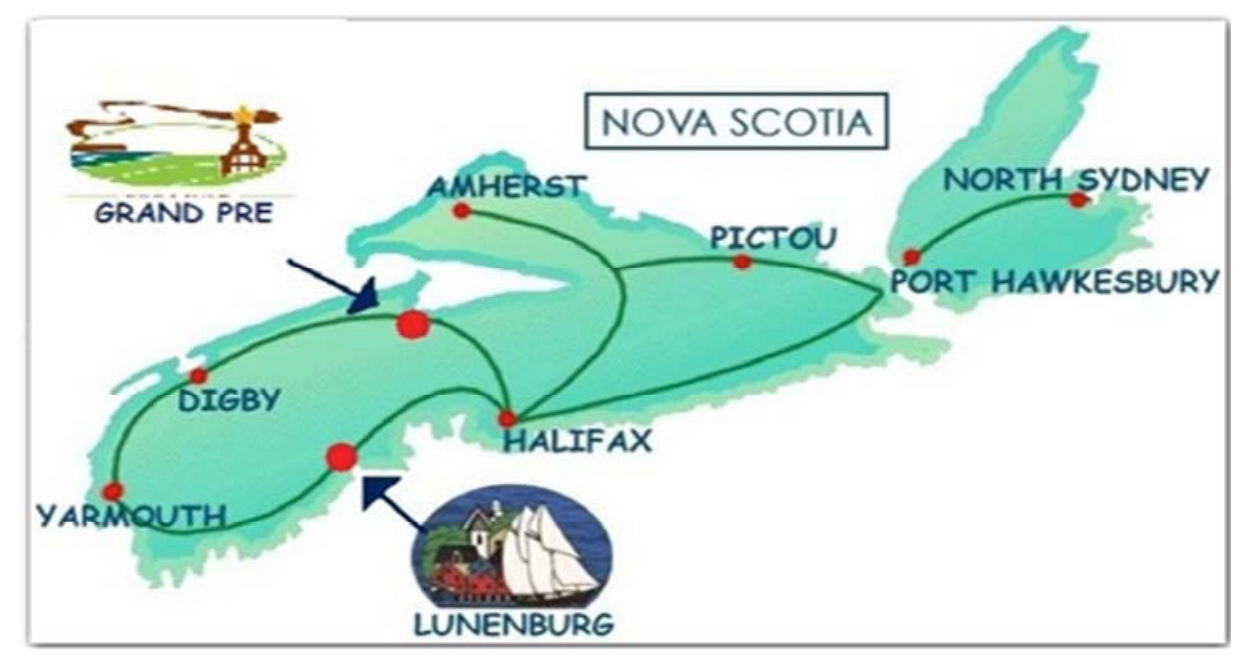

World Heritage designation offers a refreshed raison d'être for Grand Pré and area - not only a renewed visitor focus but also to support and sustain the agricultural industry that thrives on this land. It offers the opportunity for new economic development and new views on the historic tale of Grand Pré. (page 25) Grand Pré and area partners who are working to

\footnotetext{
${ }^{21}$ See Kennedy (1997) and Hamilton et al. (2004) for a detailed discussion

${ }^{22}$ See section 7.2 of the report for a detailed discussion of the strategies proposed for promotion of tourism.
} 
achieve World Heritage status have an extraordinary opportunity "to get it right", using the platform of designation to enhance existing tourism experiences and products - and to create new, compelling experiences(page 27). With appropriate planning, marketing and management of the designated area, the number of visitors will increase significantly and visitor spending will increase measurably (page 28).

However, it is important to note that this proportional impact assumption could be violated under certain circumstances, in which case we would end up underestimating the potential impact of designation on visitation to Grand Pré. In particular, suppose that an equivalent number additional tourists that visit Lunenburg due to WH designation also visits Grand Pré, if it were to be successfully designated. In this case, the percentage change in visitation to Grand Pré would be more than the percentage change in Lunenburg since the level of visitation to Lunenburg is higher than the level of visitation in Grand Pré. ${ }^{23}$ Moreover, an increase in the number of WH sites in Nova Scotia could also increase the level of visitation to Nova Scotia. This is known as the "network effect" in the literature. The addition of new WH sites has the potential to elevate consumers' understanding of the UNESCO WH Site designation rather than devaluing perceptions of the brand (Research Consulting Ltd. \& Trends Business Research Ltd., 2009). Therefore, we acknowledge the fact that the potential impact of the designation to Grand Pré could be in fact larger if either of the conditions explained above were to be realized.

\section{Appendix B - Regression Model and Results}

\section{B.1 Regression Model}

There exists no direct data on tourism visitation to Lunenburg before or after the WH designation. Therefore, visitation to Lunenburg is estimated econometrically using various data collected from the Nova Scotia Department of Tourism:

(i) Estimates of room nights sold ${ }^{24}$ from 1990-2008,

(ii) Data on non-resident visitors to Nova Scotia (1990-2008),

(iii) 2004 Exit Survey ${ }^{25}$

The dependent variable, PV NS Lt, represents the percentage of visitors coming to Nova Scotia that visit Lunenburg. The dependent variable is computed by the following equation:

${ }^{23}$ The average visitation to Old Town Lunenburg was 428,000 as opposed to 45,000 people visiting Grand Pre' Historic Site in the 2002-2008 period.

${ }^{24}$ These figures are based on figures from a sample of Lunenburg accommodation establishments.

${ }^{25}$ The survey identifies the proportion of non-resident visitor parties to Nova Scotia that travelled to/stayed in Lunenburg, average length of stay and party size. 
KAYAHAN, VANBLARCOM Analysis of UNESCO World Heritage Site Designation

$$
P V N S L_{t}=\frac{Y_{1}}{Y_{2}}=\frac{\text { Number of parties visiting Lunenburg }}{\text { Number of parties visiting Nova Scotia }}
$$

$\mathrm{Y}_{1}$, the number of parties visiting Lunenburg, is found by taking the accommodation nights sold in Lunenburg, and dividing it by the average length of stay. This approach has been taken to avoid double counting the groups staying more than one night in Lunenburg. This number is then multiplied by the ratio of total visitors to those who stayed overnight in order to include those visitors who came to Lunenburg but did not stay overnight. Y1 is calculated as shown in the following equation:

$$
Y_{1}=\frac{\text { Accommodation nights sold }}{\text { Accommodation nights stayed }} * \frac{\text { Total visitors to Lunenburg }}{\text { Overnight visitors to Lunenburg }}
$$

$\mathrm{Y}_{2}$, the number of parties visiting Nova Scotia, is calculated by taking the number of visitors to Nova Scotia and dividing it by the average party size. This is shown in the following equation:

$$
Y_{2}=\frac{\text { Total number of visitors to Nova Scotia }}{\text { Average party size }}
$$

Length of stay, the proportion of visitors to Lunenburg that stay overnight and party size estimates are obtained from the Nova Scotia Exit Survey conducted in 2004. The ratio of parties visiting Lunenburg, to parties visiting Nova Scotia, indicates the percentage of parties who come to Nova Scotia that visit Lunenburg in a given year. Henceforth, rather than referring to the percentage change in the number of parties due to UNESCO designation, it is simply identified as a change in visitation.

UNESCO is an indicator variable that takes the value of " 0 " before the World Heritage designation and the value of " 1 " after the designation. The goal of the regression is to isolate the $\beta 1$ coefficient in order to quantify the impact of the UNESCO designation on visitation to Lunen- burg. Holding the other variables constant, the percentage change in tourism to Lunenburg due to the UNESCO designation can be estimated and applied to visitation numbers at Grand Pré in order to forecast the expected impact of such a designation.

The USCANFX variable represents the US-Canada exchange rate, which denotes the value of CAN \$1 in terms of American Dollars. The United States has the largest total of visitors from a foreign country, and the exchange rate can influence the decision of American tourists to visit Canada. Assuming movements in the Canadian dollar/US dollar exchange rate is mirrored by other currencies; an appreciation/depreciation would generate an expected decrease/increase in international tourists. 
The INFLATION variable measures the annual inflation rate in the price of gas in Nova Scotia. Inflation in prices of goods and services will contribute to the expense of visiting Nova Scotia. An increase in the cost of travel due to inflation is expected to cause a decrease in the visitation to the area.

Finally, the EVENT variable is introduced in order to account for temporary increases in tourism due to particular events in the area of interest. This variable takes the value " 1 " if in that particular year there was a high profile tourism event that occurred in the region and the value "0" otherwise. "Tall Ships Nova Scotia" festival can be given as an example to such an event which brought a significantly larger portion of tourists to Lunenburg than would have otherwise occurred. A positive impact on the percentage of visitors to Lunenburg will be expected when high profile tourism event occurs.

\section{B.2 Regression Results}

The coefficient of the USCANFX variable is equal to 0.148 , implying that a one unit increase in the Canadian dollar (CAD) will lead to a $0.15 \%$ increase in the share of Nova Scotia tourists that visits Lunenburg. The coefficient maintains an incorrect sign since an appreciation of the CAD should have a negative impact on tourism. However, the impact is statistically insignificant as shown by the p-value. The INFLATION coefficient indicates that $1 \%$ increase in the price of gas would result in a $0.016 \%$ decrease in the share of visitation coming to Lunenburg out of Nova Scotia. The impact of inflation rate is concluded to be statistically insignificant at the 5\% level. The EVENT coefficient indicates that a high profile tourist event in the Lunenburg region increases the proportion of visitors who come to Nova Scotia that visit Lunenburg by $0.61 \%$ on average. This variable is significant at the $10 \%$ level. ${ }^{26}$

\section{Appendix C - Sensitivity Analysis for Visitation to Grand Pré}

To conduct a sensitivity analysis, a confidence interval around the regression coefficient, that measures the impact of WH designation on visitation in Lunenburg, is constructed. Using the regression estimate of $1.24 \%$ and the estimated standard error of 0.326 , we can repeat method- ology outline earlier to compute the low and high estimates for the percentage increase in visitation to Lunenburg (at the $95 \%$ confidence level) are $2.7 \%$ and $9.7 \%$ respectively. The same impact analysis for visitation and spending due to UNESCO, as previously developed, can be constructed with high and low values to estimate the impact of

${ }^{26}$ Few significant variables combined with a significant F-statistic may result from multicollinearity in the data. The largest value of the Variance Inflation Factor (VIF) for the set of our independent variables is 1.22 , which is lower than the cutoff value of 10 , indicating that multicollinearity is not a problem in the data. One potential reason for insignificance of inflation and exchange rate coefficients might be the small sample size in the data. 
KAYAHAN, VANBLARCOM Analysis of UNESCO World Heritage Site Designation

designation on visitation spending under each of the historical and forecasted scenarios. These results are shown in Table 7. Taking the historical visitation average of 48,450 the low and high bound estimates of change in visitation implies that WH designation could increase visitation as little as 1,298 visitors and as many as 4,710 visitors. Additional spending associated with the designation ranges from $\$ 86,562$ to $\$ 314,158$. Under the projected scenario, forecasted number of visitors for 2009 is 23,419 . The low and high bound estimates of the impact of designation are 627 visitors and 2,277 visitors respectively. Corresponding visitor spending is estimated at a low of $\$ 41,841$ and a high of $\$ 151,853$. 